\title{
Rhizoctonia crown and root rot of the pasture legume, sulla (Hedysarum coronarium)
}

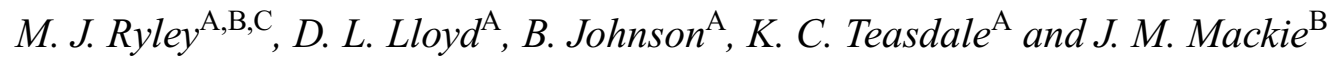

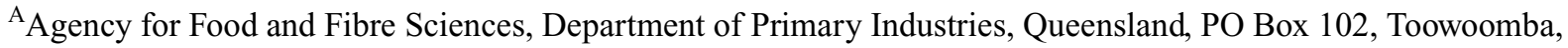 \\ Qld 4350, Australia. \\ ${ }^{B}$ Cooperative Research Centre for Tropical Plant Protection, Level 5 John Hines Building, The University of \\ Queensland, St Lucia, Qld 4072, Australia. \\ ${ }^{\mathrm{C}}$ Corresponding author; email: malcolm.ryley@dpi.qld.gov.au
}

\begin{abstract}
Rhizoctonia solani AG-2-2 was isolated from wilting and dying plants of sulla (Hedysarum coronarium), which is currently being assessed in eastern and southern Australia for its potential as a pasture and forage legume. Infected plants in the field had extensive rotting of the taproot, lateral roots and crown. Koch's postulates were fulfilled using three inoculation methods. The disease may pose a considerable threat to the potential use of $H$. coronarium in the dryland, grazing farming systems of Australia, with resistance offering the most viable option for minimising its impact.
\end{abstract}

\section{Introduction}

There are approximately 150 species of the temperate legume Hedysarum. At least 23 of these have been introduced into Australia as potentially useful forage plants, predominantly from the Mediterranean basin of southern Europe, the Middle East and northern Africa, but also from China and the former USSR. Some species, particularly H. coronarium (sulla), are of significant agricultural importance. Sulla is naturalised in 25 countries including Australia (Stanley and Ross 1983), although it is confirmed as a native plant in only five countries in northern Africa and southern Europe (White 2003). It has been used widely for fodder and hay in Mediterranean Europe (Whyte et al. 1953) and is currently being used in New Zealand for these purposes (Anonymous 2001).

Sulla (syn. Spanish or Italian sanfoin, French honeysuckle, Sulla sweet vetch) is a short-lived, taprooted, herbaceous perennial and, although adapted to calcareous soils, it grows at pH 5.5-8.0 (Anonymous 2001). There is a wide range of habit form, from prostrate types that may be better suited for grazing, to semi-erect and erect types that may be better suited for hay or green manure. Erect types grow to $1.6 \mathrm{~m}$ tall. Sulla has a high content of condensed tannins that protect proteins from rumen degradation and confer non-bloating and anthelminthic attributes. Sulla is dormant during the summer but produces high quantities of biomass between autumn and spring (de Koning et al.
2003). It is an outcrossing species that is pollinated by bees.

A detailed evaluation of the most promising accessions characterised by the Australian Medicago Genetic Resource Centre, SARDI, Adelaide (S. Hughes, personal communication), was commenced in 2000 in South Australia and Queensland and, to a limited extent, in northern New South Wales within the National Annual Pasture Legume Improvement Program (NAPLIP) (de Koning et al. 2003). In December 2000, wilted plants of $H$. coronarium growing in a NAPLIP field trial at Downfall Creek, Queensland (approx. $26^{\circ} 15^{\prime} \mathrm{S}, 150^{\circ} 09^{\prime} \mathrm{E}$ ) were observed, although, at this time, the level of plant mortality was low. The soil at the site is an alkaline, cracking clay. Affected plants were initially characterised by red, yellow and bronzed leaf discoloration, followed by wilting of the leaves and petioles. Below ground, the taproot and lateral roots were extensively rotted, with red-dark brown lesions on the crown. Rhizoctonia solani was consistently isolated from the affected plant tissue. Later, plants with identical symptoms to the wilted plants at Downfall Creek were found in H. coronarium accessions at another NAPLIP evaluation site north of Glenmorgan (approx. $27^{\circ} 06^{\prime} \mathrm{S}, 149^{\circ} 33^{\prime} \mathrm{E}$ ) in southern Queensland. The soil at this site is an alkaline, red-brown, loamy, duplex soil. Thirty H. coronarium accessions had been sown in June 2000 and good stands were established in all of the plots (range 43-91 plants $/ \mathrm{m}^{2}$ ). The populations were maintained during 
the first winter-spring season in 2000 , but by June 2001 severe losses were evident in all 30 lines. In some plots, every plant died and even in treatments with the highest survival rates fewer than $1 \mathrm{plant} / \mathrm{m}^{2}$ survived.

Surviving plants were removed from the Glenmorgan site in October 2001 ( $\sim 180$ plants) and from the Downfall Creek site in August 2003 ( $\sim 50$ plants) and transplanted into pots at Toowoomba for use in a plant breeding program.

This paper describes the symptoms of the disease, reports on the fulfilment of Koch's postulates, and discusses the options for screening protocols for identifying possible sources of resistance in $H$. coronarium to the pathogen.

\section{Methods}

\section{Original isolations from plants}

Infected plants collected from the Downfall Creek site in December 2000 were forwarded to the Cooperative Research Centre for Tropical Plant Protection, The University of Queensland, St Lucia, Queensland. The roots were excised, washed in running water for 2 min, scrubbed lightly to remove adherent soil, then blotted dry with paper towel. Infected taproots were cut longitudinally with a sterile knife and 2-mm-long sections of the internal discoloured tissue were excised and placed on the surface of potato-dextrose agar (PDA) (Difco) in 9-cm-diameter plastic Petri dishes, which were incubated at $27^{\circ} \mathrm{C}$ under black light. After 9 days, the colonies were examined and two colonies with characteristics of Rhizoctonia spp. were subcultured on fresh plates of PDA. Two isolates (UQ5610 and UQ5611, collectively deposited as BRIP39733) were stored as colonised agar blocks in sterile distilled water in $20 \mathrm{~mL}$ McCartney bottles at room temperature. The isolates were forwarded to the Department of Primary Industries Plant Pathology laboratories at Toowoomba, Queensland, in mid-2002 where the pathogenicity tests described below were conducted. Both isolates were hyphal-tipped and a subculture of each was forwarded to Ms D. Wright, Department of Agriculture, Western Australia, for Anastomosis Group (AG) determination. Other subcultures were stored as colonised agar blocks in sterile water in $20 \mathrm{~mL}$ McCartney bottles at $15^{\circ} \mathrm{C}$ in darkness.

\section{Pathogenicity tests}

Three inoculation methods were used. The first involved a layer of inoculum (three rates of inoculum) at two depths below the seed, the second involved placing a Rhizoctonia-colonised barley seed against the basal portion of the stem of 46-day-old plants, and the third involved pouring macerated mycelium on the surface of potting mix in which 46-day-old plants were growing.

For the inoculum layer inoculations, $500 \mathrm{~g}$ of a cornmeal-sandwater mix (3:97:15) (Carling and Sumner 1992) was placed in $27 \mathrm{~cm}$ $\times 22 \mathrm{~cm} \times 3 \mathrm{~cm}$ metal trays, enclosed in an autoclave bag then autoclaved at $121^{\circ} \mathrm{C}$ and $140 \mathrm{kPa}$ for $20 \mathrm{~min}$. After the medium had cooled, $100 \mathrm{~mL}$ of sterile distilled water was added to each tray and incorporated through the mix using a sterile metal spoon. The trays were returned to the autoclave bags after six $10 \mathrm{~mm} \times 10 \mathrm{~mm}$ blocks of agar colonised by either UQ5610 or UQ5611 had been placed at approximately equidistant locations on the cornmeal-sand medium. They were then placed on a laboratory bench and incubated under ambient conditions (diffuse sunlight and fluorescent lights, $24^{\circ} \mathrm{C} \pm 2^{\circ} \mathrm{C}$ ) for 14 days. Each isolate was inoculated onto the medium in two trays.

A potting mixture consisting of coarse sand and soil (1:1) was steam sterilised for $30 \mathrm{~min}$ at $80^{\circ} \mathrm{C}$. On 14 October 2002, soil was added to 14-cm-diameter pots to a depth of either 7 or $9 \mathrm{~cm}$ below the top of the pot. A layer of inoculum of a mixture of the two isolates (1:1) consisting of $144 \mathrm{~g}$ (high), $72 \mathrm{~g}$ (medium) or $7.2 \mathrm{~g}$ (low) of the colonised cornmeal-sand mix (7.4\% moisture) was placed on the potting mix surface. Potting mix was added until it was $2 \mathrm{~cm}$ below the pot rim, then 12 seeds of $H$. coronarium cv. Aokau were sown in each pot and covered with $1 \mathrm{~cm}$ of mix. Plants growing in potting mix that did not contain inoculum were used as controls. Each pot contained $2.1 \mathrm{~kg}$ of potting mix plus inoculum. There were four replicate pots of each inoculum rate $\times$ inoculum depth combination, and one control pot per replicate. All pots were placed in a randomised design in a glasshouse, watered daily and fertilised using a 1.5\% Aquasol [Hortico (Aust.) Pty Ltd] solution once a week. Eighteen days after emergence, plants in the control pots were thinned to six plants/pot, whereas plants in the pots containing inoculum were not thinned.

The number of healthy plants and those displaying wilting were counted every second day from emergence onwards ( 9 days after sowing). Fifty days after inoculation, the surviving plants were carefully removed from the potting mix and the roots washed and excised from the stems. The roots of three plants displaying symptoms of rotting were used to isolate the causal agent, the methodology being the same as that described above for the initial isolations from field plants. The dry weights of roots and above ground parts were determined by bulking each component from the surviving plants in a pot, placing them in an oven in paper bags at $80^{\circ} \mathrm{C}$ for $48 \mathrm{~h}$, then weighing each sample. These data were used to determine the effects of inoculum concentration $\times$ inoculum depth combinations on the shoot and root weights of surviving plants.

For the barley seed and mycelium inoculum tests, six plants of H. coronarium cv. Aokau were grown for 46 days in the sterile sand-soil mix in 14-cm-diameter pots under glasshouse conditions described above. Inoculum for the barley seed test was prepared by sterilising barley seed at $121^{\circ} \mathrm{C}$ and $140 \mathrm{kPa}$ for 20 min then sowing the seed onto a 1-week-old colony of isolate UQ5610 growing on the cornmeal-sand medium described above. This mixture was incubated for 2 weeks on a laboratory bench under ambient conditions $\left(24^{\circ} \mathrm{C} \pm\right.$ $2^{\circ} \mathrm{C}$ ). A single colonised seed was placed directly against the stem of each plant, just below soil level, in 16 pots. For the mycelium inoculum test, each isolate was grown in $500 \mathrm{~mL}$ of V-8 juice broth $(200 \mathrm{~mL}$ Campbell's V-8 juice $+800 \mathrm{~mL}$ distilled water $+10 \mathrm{~g}$ calcium carbonate) in $1.5 \mathrm{~L}$ Erlenmeyer flasks for 2 weeks on the same laboratory bench. The mycelium was harvested by pouring the broth through two layers of muslin, then squeezed dry, initially in the muslin and later between paper towels (to approximately $70 \%$ moisture content). Three inoculum rates, 1,5 , or $10 \mathrm{~g}$ inoculum/pot (low, medium and high, respectively), consisting of a 1:1 mixture of the two isolates, were used in the test. For each rate, the appropriate weight of mycelium was added to $1 \mathrm{~L}$ distilled water and blended for $20 \mathrm{~s}$. In each of four pots, $250 \mathrm{~mL}$ of each inoculum suspension was poured onto the surface of the potting mix around the plants. Plants in four pots to which no inoculum was added served as controls for both the barley seed and mycelium inoculum tests. The plants were grown in a randomised design in the glasshouse and watered daily, and after 41 days the numbers of surviving plants in each pot were counted, and the fresh and dry weights of the roots and above ground parts were determined, as described above. The causal agent was isolated from three wilted plants in each of the tests, using the method described above.

Analyses of variance were conducted using Genstat v 6.1 (Lawes Agricultural Trust, Rothamsted Experimental Station). All significant differences are at $P \leq 0.05$.

\section{Results}

\section{Symptoms on field plants}

The leaves and petioles of affected plants were wilted, and there was a red, yellow or bronze discoloration over the entire 


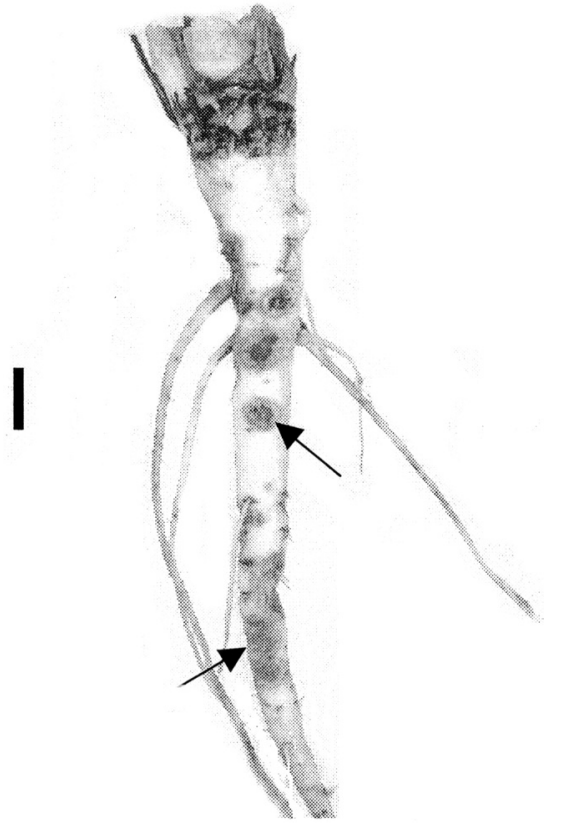

Fig. 1. Lesions caused by Rhizoctonia solani on a taproot of sulla (Hedysarum coronarium). Arrows indicate some lesions of $R$. solani. Bar represents $5 \mathrm{~mm}$.

leaf surface. On some plants collected from Downfall Creek, elongated lesions covered most of the upper portions of the taproots, whereas on other taproots the lesions were circular and tended to be at the junction between the lateral roots and the taproot (Fig. 1). In all cases the lesions were red to light-brown and sunken. On the worst affected plants, the basal portions of the taproot had rotted off. Internally, there was a clear boundary between the brown, rotted, root tissue and the white, healthy, root tissue. There were discrete, elongated, red to light-brown lesions on some of the lateral roots.

\section{Colony characteristics and isolate identity}

The two isolates from the field-affected plants had identical colony morphology. Seven-day-old colonies growing on PDA in the dark at $26^{\circ} \mathrm{C}$ covered the entire surface of a 9-cm-diameter Petri dish, with the mycelium a thin felt, tufted in the centre, and mostly light-brown with darker brown concentric rings around the light-brown centre. At the margin of the colonies, the mycelium was slightly raised and denser than in the remainder. One-month-old colonies were brown, with dark-brown concentric rings and a dark-brown, 4-7 cm-wide region around the margin. Raised, hemispherical sclerotia, up to $2 \mathrm{~mm}$ wide and with a rough, uneven surface, were distributed at random across the surface of the colonies. Hyphae near the expanding colony margin were hyaline, thin-walled, 5-6 $\mu \mathrm{m}$ in diameter, with dolipore septa and cells 40-150 $\mu \mathrm{m}$ long. Branches, which arose near the middle of the cells at right angles to the hyphae, were constricted just above the origin and each had a septum shortly above that point. Older hyphae were slightly

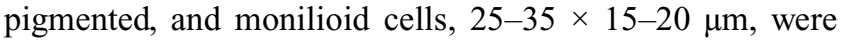
common. The sclerotia consisted of highly pigmented, roughly globose cells, $15-30 \mu \mathrm{m}$ wide. Both isolates were identified as Rhizoctonia solani AG-2-2 (D. Wright, personal communication).

\section{Symptoms on plants after inoculation}

In the inoculum layer test, the first wilted plants were observed 11 days after sowing. Initially, the leaves became flaccid and petioles drooped, and within 14 days all the petioles on an infected plant had wilted. All infected plants from the inoculated pots had similar symptoms, although their severity varied. The lateral roots were severely pruned, and there were brown to red lesions, varying in length from $<1$ to $5 \mathrm{~cm}$, on most lateral roots. On some infected plants, the taproot was pruned, often to within $1 \mathrm{~cm}$ of the base of the stem. The surfaces of the taproots of all infected plants were light brown-red, particularly on their upper portions. Plants in control pots were characterised by a vigorous root system composed of a long, thick, white taproot with numerous white, fibrous, lateral roots. There were no significant differences in the percentage of survivors [(no. survivors at harvest / no. emerged) $\times 100$ ] between the inoculum rate $\times$ depth combinations, with values ranging from 7 to $16.2 \%$. The mean dry weights of plant tops of surviving plants for all inoculum rate $\times$ depth combinations except the low rate $\times 5 \mathrm{~cm}$ treatment were significantly less than the corresponding values for the non-inoculated control treatment (Fig. 2). For root dry weight, there were no significant differences between the control plants and those in all three 5-cm-layer treatments. However, the corresponding values for all 7-cm-layer treatments were significantly less than the control treatment. All plants in the non-inoculated control treatment survived from thinning to harvest, and none displayed symptoms of infection by R. solani.

Symptoms of Rhizoctonia infection on plants inoculated with a single barley seed, colonised with isolate UQ5610, appeared 6 days after inoculation. Wilting and death of the foliage progressed rapidly due to the rotting of the basal portion of the stem at the point of inoculation. On most infected plants at harvest, there were no lateral roots and the taproot had been reduced to a short stump. On a few infected plants, lateral roots grew from the healthy upper portion of the taproot. In the mycelial inoculum test, plants began wilting 11 days after inoculation, and followed a similar pattern of symptom development to plants in the inoculum layer test. At harvest, the symptoms on roots were identical with those described above. There were significantly fewer survivors in the colonised barley seed test $(43.8 \%)$ than in the mycelial inoculum test $(62.5-70.8 \%)$, and there were no significant differences in 


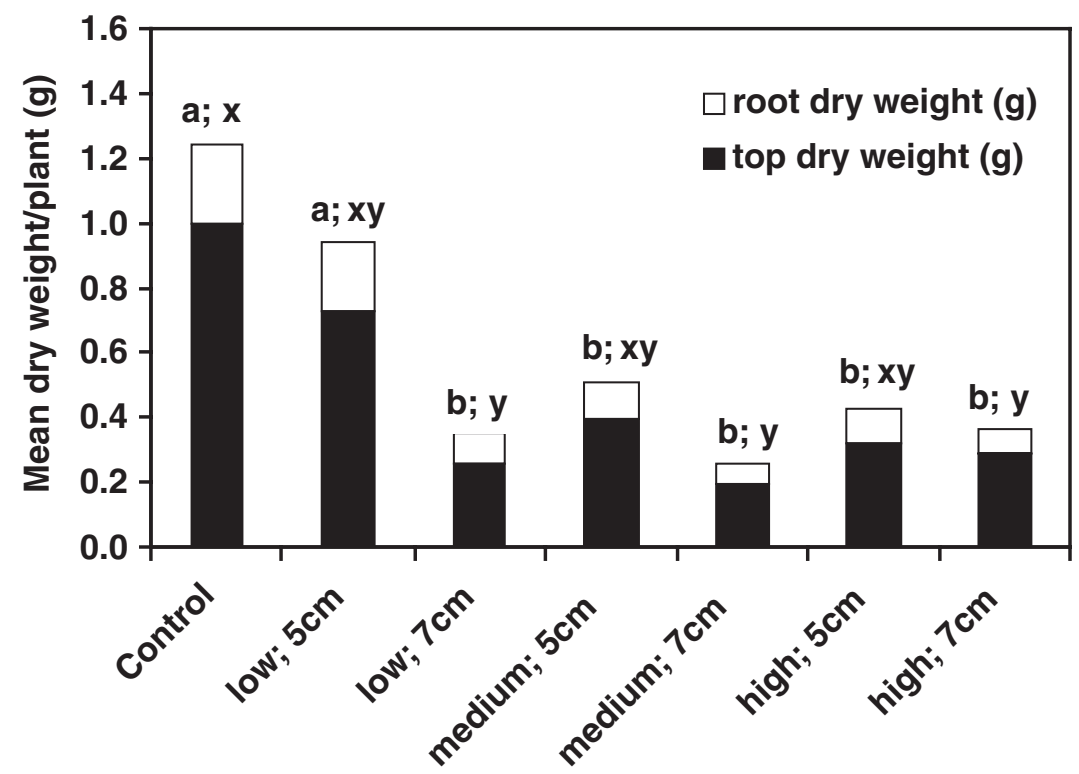

Inoculum concentration, and depth (cm)

Fig. 2. Inoculum layer test; mean top and root dry weights of surviving plants at different inoculum concentrations (low, $7.2 \mathrm{~g}$ inoculum/pot; medium $72 \mathrm{~g} /$ pot; high $144 \mathrm{~g} /$ pot) and depths ( $7 \mathrm{~cm}$ or $5 \mathrm{~cm}$ below seeds). Columns with different letters are significantly different $(P=0.05)$ for top $(\mathrm{a}, \mathrm{b})$ and root $(\mathrm{x}, \mathrm{y})$ dry weights.

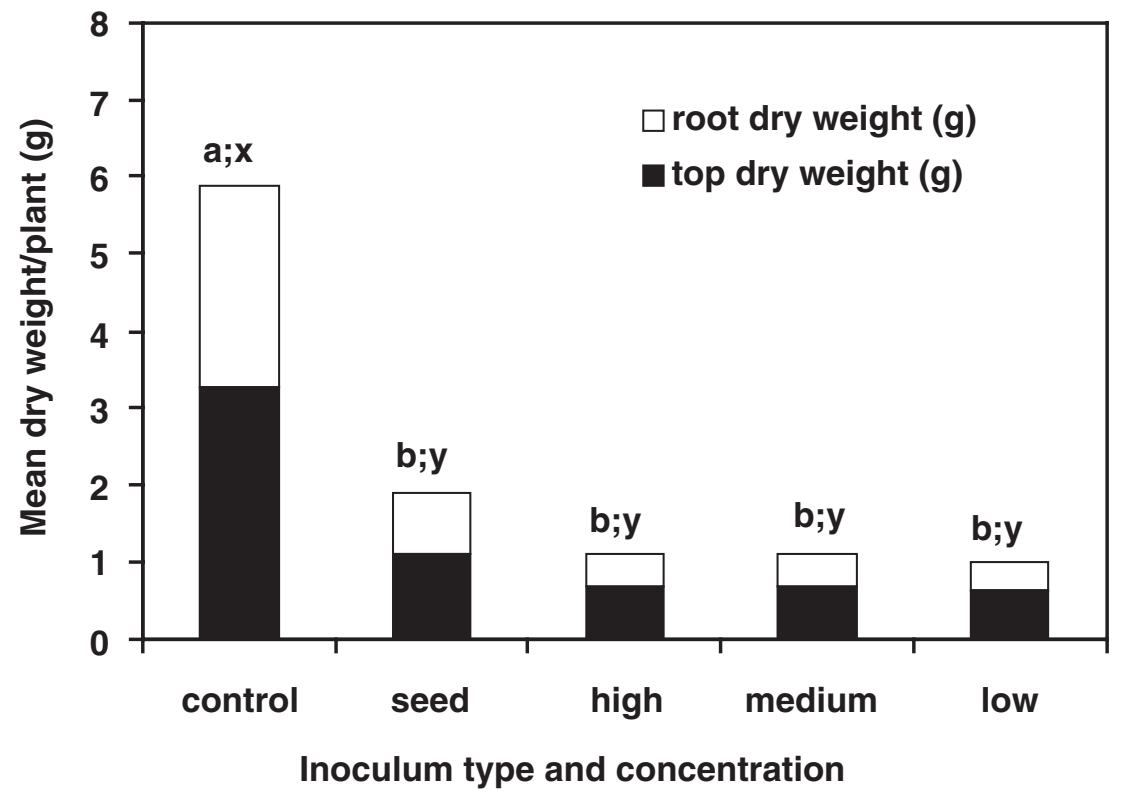

Fig. 3. Mycelium and barley seed inoculum tests; mean top and root dry weights of surviving plants at different inoculum types (colonised barley seed or mycelium) and concentrations (mycelium low, $1 \mathrm{~g} /$ pot; medium, $5 \mathrm{~g} / \mathrm{pot}$; high, $10 \mathrm{~g} / \mathrm{pot}$ ). Columns with different letters are significantly different $(P=0.05)$ for top $(a, b)$ and $\operatorname{root}(\mathrm{x}, \mathrm{y})$ dry weights.

the percentage of survivors between the three inoculum rates in the mycelium inoculum test. Plants in the control treatment did not display any signs or symptoms of infection by $R$. solani or any other pathogen. The values of mean top and root dry weights of surviving plants were significantly lower at all inoculum types and concentrations than the corresponding values for the plants in the non-inoculated control treatment (Fig. 3). 
During the course of the inoculum layer test (15 October 2002 to 4 December 2002) the range and (mean values) for temperature and relative humidity in the glasshouse were $18.5-29^{\circ} \mathrm{C}(24.0 \pm 2.2)$ and $27.8-86.4 \%(54.9 \pm 12.4)$, respectively, while during the course of the infected barley seed and the fungal inoculum tests (29 November 2002 to 9 January 2003) the values were $17.9-27.6^{\circ} \mathrm{C}(22.9 \pm 1.9)$ and $24.9-91.1 \%(67.7 \pm 12.3)$, respectively.

\section{Characteristics of isolates from inoculated plants}

The colonies of the isolates collected from the roots of plants inoculated by the three methods were identical in all respects to those that were collected initially from the affected field plants and that were identified as Rhizoctonia solani AG-2-2.

\section{Discussion}

To our knowledge, this is the first published report of Rhizoctonia solani on sulla (Hedysarum coronarium). Other hosts recorded for $R$. solani AG-2-2 (or subgroups of AG-2-2) include lucerne (Medicago sativa), soybean (Glycine max), sugar beet (Beta vulgaris), lima bean (Phaseolus lunatus), sweet pea (Lathyrus odoratus), maize (Zea mays) and sorghum (Sorghum bicolor) (Liu and Sinclair 1991), snap bean (Phaseolus vulgaris) and cowpea (Vigna sinensis) (Sumner 1985), wheat (Triticum aestivum) and barley (Hordeum vulgare) (Furgal-Wegrzycka et al. 1998), and several other grasses (Haygood and Martin 1990; Herr and Fulton 1995). In Western Australia, AG-2-2 has been reported on subterranean clover (Wong and Sivasithamparam 1985; MacNish et al. 1994), lupin (Lupinus angustifolius) and barley (MacNish et al. 1994), and it was isolated by MacNish et al. (1994) from a grass-legume pasture at Kojaneerup and from soil at Esperance.

There is limited information on the diversity and distribution of different anastomosis groups on pasture legumes in Australia. $R$. solani AG-8, which is known to infect wheat and barley (MacNish et al. 1994; Gill et al. 2001), and AG-2-1 which infects lupin, canola (Brassica napus) (R. Hutton, personal communication), barley and subterranean clover (MacNish et al. 1994) have been isolated from annual Medicago species in the temperate zones of southern Australia (Streeter et al. 2001; R. Hutton, personal communication). MacNish et al. (1995) isolated AG-10 from the roots of subterranean clover in a grass-legume pasture, and from faba bean (Vicia faba), lupin, wheat and barley in Western Australia.

Sulla is a productive forage legume with the potential to become an important complement to lucerne and other temperate forage species on alkaline soils in the southern Australian wheatbelt (Dear et al. 2003). In Queensland, root canker of lucerne caused by $R$. solani is confined mainly to soils with restricted drainage, in areas receiving less than $650 \mathrm{~mm}$ of average annual rainfall (Irwin 1977; Lowe et al.
2002). Sulla is currently being assessed as a complement to lucerne and annual medics in these areas. Limited investigations have revealed that $R$. solani isolates from lucerne in some of these regions belong in a group with some of the characteristics of AG-6 (J. Irwin, personal communication). In the United States, AG-2-2 has been reported to be pathogenic to lucerne roots and stems under artificial inoculation conditions (Liu and Sinclair 1991). Other AG groups, AG-3, AG-4, AG-5, AG-10, AG-I are pathogenic to lucerne roots (Vincelli and Herr 1992; Eken and Demirci 2003), while AG-1 has been reported as causing web blight on lucerne leaves (Vincelli and Herr 1992).

In legume pastures, where there is little or no potential to apply expensive options (such as fungicides) for the management of $R$. solani, resistance offers the best long-term solution. Germplasm with resistance to $R$. solani has been identified in some legumes including annual and perennial Medicago spp. (Kulik and Dery 1995), and subterranean clover (Barbetti et al. 1986; Nichols et al. 1995). It is possible that there are also sources of resistance to this pathogen within $H$. coronarium and other species of Hedysarum. Work will soon commence to determine the levels of resistance to $R$. solani in some $H$. coronarium accessions that have shown promise in Queensland.

Barbetti (1990) used a mycelial concentration of $0.2 \%$ (mass air-dried mycelium:mass air dried soil) in his studies with $R$. solani on subterranean clover. We found no significant differences in the percentage of survivors, and in the mean root and shoot dry weights of surviving plants between the three rates of inoculum $(1 \mathrm{~g}, 5 \mathrm{~g}$ and $10 \mathrm{~g}$ of inoculum per pot; equivalent to $\sim 0.05 \%, 0.24 \%$ and $0.48 \%$ mycelium weight:potting mix weight, respectively) that were used. Although there was a similar relationship for five of the six inoculum concentration $x$ inoculum depth combinations, the percentage of survivors in this experiment $(7-16.2 \%)$ was much lower than in either the barley seed test $(43.8 \%)$ or the mycelium inoculum test $(62.5-70.8 \%)$. We intend to use a variation of the inoculum layer test described above to assess the relative levels of resistance of $H$. coronarium accessions to $R$. solani AG-2-2, because the high rates of mortality in the inoculum layer test were similar to those observed at the two field sites.

The role of $R$. solani in reducing the establishment of pasture legumes in Australia was demonstrated by Pankhurst et al. (1998). Given the presence of AG-2-2 on several hosts in Queensland and in the temperate regions of southern Australia, it is likely that the pathogen will have an impact on the establishment and persistence of sulla in some areas, unless resistant or tolerant cultivars are developed.

\section{Acknowledgements}

The authors thank Ms Susanne O'Brien (Department of Primary Industries, Queensland) for technical assistance, Ms Kerry Bell (Department of Primary Industries, Queensland) 
for statistical analyses and Ms Dominie Wright (Department of Agriculture, Western Australia) for AG testing. Funding provided by GRDC and the Department of Primary Industries, Queensland, is gratefully acknowledged.

\section{References}

Anonymous (2001) 'Sulla.' Popular brochure, AgResearch, NZ.

Barbetti MJ (1990) Effect of adding lime to potting soil on the pathogenicity of four root pathogens of subterranean clover. Phytophylactica 22, 245-249.

Barbetti MJ, Wong DH, Sivasithamparam K, D'Antuono MF (1986) Response of subterranean clover cultivars to root rot fungi. The Annals of Applied Biology 109, 259-267.

Carling DE, Sumner DR (1992) Rhizoctonia. In 'Methods for research on soilborne phytopathogenic fungi'. (Eds LL Singleton, JD Mihail, CM Rush) pp. 157-165. (APS Press: St Paul, MN, USA)

Dear BS, Moore GA, Hughes SJ (2003) Adaptation and potential distribution of temperate perennial legumes to the southern Australian wheat belt: a review. Australian Journal of Experimental Agriculture 43, 1-18.

De Koning C, Lloyd D, Hughes S, McLachlan D, Crocker G, Craig A (2003) Hedysarum, a new temperate forage legume with great potential - field evaluation. In 'Solutions to a better environment'. Proceedings of 11th Australian Agronomy Conference, 2-6 February 2003, Geelong, Victoria. (Eds M Unkovich, G O'Leary) (Australian Society of Agronomy, CD Rom ISBN 0-9750313-0-9)

Eken C, Demirci E (2003) Identification and pathogenicity of Rhizoctonia solani and binucleate Rhizoctonia anastomosis groups isolated from forage legumes in Erzurum, Turkey. Phytoparasitica 31, 76-80.

Furgal-Wegrzycka H, Adamiak J, Adamiak E (1998) Some characteristics of isolates of Rhizoctonia solani from patch of wheat and barley. Acta Mycologica 33, 109-121.

Gill JS, Sivasithamparam K, Smettem KRJ (2001) Influence of depth of soil distribution on root dynamics of wheat seedlings associated with Rhizoctonia solani AG-8 disease severity in sandy and loamy soils of Western Australia. Soil and Tillage Research 62, 73-83. doi:10.1016/S0167-1987(01)00217-3

Haygood RA, Martin SB (1990) Characterization and pathogenicity of species of Rhizoctonia associated with centipedegrass and St. Augustinegrass in South Carolina. Plant Disease 74, 510-514.

Herr LJ, Fulton MM (1995) Rhizoctonia solani AG-1-1A and AG-2-2 IIIB cause brown patch on tall fescue and creeping bentgrass in Ohio. Plant Disease 79, 1186.

Irwin JAG (1977) Factors contributing to poor lucerne persistence in Queensland. Australian Journal of Experimental Agriculture and Animal Husbandry 17, 998-1003.

Kulik MM, Dery PD (1995) Frequency of plants in populations of annual and perennial medics (Medicago spp.) that were resistant to damping-off incited by AG 4 isolates of Rhizoctonia solani. Zeitschrift fur Pflanzenkrankheiten und Pflanzenschutz 101, 392-398.
Lowe KF, Lloyd DL, Bullen KS (2002) Understanding more about lucerne. In 'The lucerne management handbook (4th edn)'. (Ed. K Bullen) pp. 1-11. (Department of Primary Industries: Brisbane, Qld)

Liu Z, Sinclair JB (1991) Isolates of Rhizoctonia solani anastomosis group 2-2 pathogenic to soybean. Plant Disease 75, 682-687.

MacNish GC, Carling DE, Sweetingham MW, Brainard KA (1994) Anastomosis group (AG) affinity of pectic isozyme (zygogram) groups (ZG) of Rhizoctonia solani from the Western Australian cereal-belt. Mycological Research 98, 1369-1375.

MacNish GC, Carling DE, Sweetingham MW, Ogoshi A, Brainard KA (1995) Characterisation of anastomosis group-10 (AG-10) of Rhizoctonia solani. Australasian Plant Pathology 24, 252-260.

Nichols PGH, Nicholas DA, Dear BS, Clark SG, Reed KFM, De Koning CT, Bellotti W, Lloyd DL (1995) Register of Australian herbage plant cultivars. B. Legumes. 1. Clover (d) Trifolium subterraneum L. var. subterraneum (Katz. et Morley) Zohary and Heller (subterranean clover) cv. York. Australian Journal of Experimental Agriculture 35, 821-822.

Pankhurst CE, Hawke BG, McDonald HJ (1998) Role of root disease in the poor establishment of Medicago pastures after cereal cropping in South Australia. Plant Pathology 47, 749-758.

Stanley TD, Ross EM (1983) Hedysarum. In 'Flora of South-eastern Queensland. Vol. 1'. p. 303. Queensland Department of Primary Industries Miscellaneous Publication No. 81020. (Department of Primary Industries: Brisbane, Qld)

Streeter TC, Rengel Z, Neate SM, Graham RD (2001) Zinc fertilisation increases tolerance to Rhizoctonia solani (AG 8) in Medicago truncatula. Plant and Soil 228, 233-242. doi:10.1023/A:10048 74027331

Sumner DR (1985) Virulence of anastomosis groups of Rhizoctonia solani and Rhizoctonia-like fungi on selected germ plasm of snap bean, lima bean, and cowpea. Plant Disease 69, 25-27.

Vincelli PC, Herr LJ (1992) Two diseases of alfalfa caused by Rhizoctonia solani AG-1 and AG-4. Plant Disease 76, 1283.

White R (2003) Hedysarum coronarium. In 'International legume database \& information service'. Available online at http://www.ildis.org/LegumeWeb/

Whyte RO, Nilsson-Leissner G, Trumble HC (1953) Hedysarum: sulla. In 'Legumes in agriculture'. (Food and Agriculture Organisation of the United Nations: Rome, Italy)

Wong DH, Sivasithamparam K (1985) Rhizoctonia spp. associated with root rots of subterranean clover in Western Australia. Transactions of the British Mycological Society 85, 21-27.

Received 7 July 2003, accepted 5 September 2003 